\title{
IMPLEMENTASI NILAI PANCASILA DALAM MENUMBUHKEMBANGKAN WAWASAN KEBANGSAAN DI KEHIDUPAN BANGSA INDONESIA
}

\author{
Siti Aisyah Nurfatimah \& Dinie Anggraeni Dewi \\ Universitas Pendidikan Indonesia \\ sitiaisyahn18@upi.edu
}

\begin{abstract}
Abstrak
Pembahasan mengenai wawasan kebangsaan merupakan suatu hal yang sangat amat penting untuk dilakukan secara terus menerus sejalan dengan kehidupan berbangsa dan bernegara. Nilai pancasila disini hadir sebagai penjembatan dalam menumbuhkembangkan wawasan kebangsaan. Pancasila sebagai pedoman hidup bangsa dan ideologi negara Indonesia mulai kehilangan pamornya dan tergantikan oleh kebudayaan asing yang terbawa oleh globalisasi. Padahal, Pancasila merupakan nilainilai yang dirumuskan dan diturunkan dari nilai-nilai bangsa Indonesia itu sendiri yang sesuai dengan adat istiadat dan kebudayaan yang ada di kehidupan bangsa Indonesia. Tujuan dari penelitian ini adalah membantu para generasi muda untuk bisa memahami dan mengenal jati diri bangsanya yang sudah mulai terlupakan. Metode penelitian yang digunakan dalam pembuatan artikel ini, yaitu dengan menggunakan metode penelitian kualitatif. Dalam metode ini penulis mengumpulkan data yang diperoleh melalui pengkajian buku, artikel, dan karya ilmah lainnya. Hasil dari penelitian ini adalah banyak sekali nilai-nilai pancasila yang bisa diimplementasikan dalam menumbuhkembangkan wawasan kebangsaan dalam kehidupan berbangsa dan bernegara. Sehingga, dengan adanya artikel ini dapat membantu para generasi menemukan jati diri bangsanya dan mulai mencintai budaya bangsanya sendiri.
\end{abstract}

Kata Kunci: Pancasila, Wawasan Kebangsaan, dan Implementasi Nilai Pancasila.

\begin{abstract}
Abstrack
The discussion of the national insight is a very important thing to be carried out continuously in line with the life of the nation and state. The value of pancasila here is present as a bridge in developing national insight. Pancasila, as a guide for the nation's life and the ideology of the Indonesian state, is starting to lose its prestige and is being replaced by a foreign culture brought on by globalization. Whereas, pancasila is the value formulated and derived from the values of the Indonesian nation itself which are in accordance with the costums and culture that exist in the life of the Indonesian nation. The purpose of this research is to help the younger generation to understand and get to know ther forgotten national identity. Of the research use in the manufacture of this article, namely by using qualitative research method. In this method, the authors collect data obtained throught reviewing books, articles and other scientific works. The result of this research is that there are a lot of pancasila values that can be implemented in developing national insight into the life of the nation and state. So, this article can help the younger generation to find their national identity to start loving their own nation's culture.
\end{abstract}

Key Words: Pancasila, National Insight, and The Implementation of Pancasila Values

\section{PENDAHULUAN}

Setiap negara di dunia ini pastinya memiliki visi bagi bangsa negaranya untuk mencapai tujuan di masa depan. Hal ini sangat berkaitan erat dengan wawasan kebangsaan. Dalam suatu negara kehidupan berbangsa memerlukan sebuah konsep atau cara pandang dengan tujuan bisa menjamin kebelangsungan kehidupan bangsa dan wilayahnya, serta mengenal jati diri dari negara tersebut. Sehingga arti dari wawasan kebangsaan itu sendiri adalah terkad kebersatuan suatu bangsa atau negara pada cita-cita dan tujuan nasionalnya (Nurgiansah, 2021a).

Pembahasan mengenai wawasan kebangsaan merupakan suatu hal yang sangat amat penting untuk dilakukan secara terus menerus sejalan dengan kehidupan berbangsa dan bernegara. 
Wawasan kebangsaan merupakan jiwa dan ruh atau semangat dari kehidupan berbangsa dari suatu negara, jiwa dan semangat dari kehidupan berbangsa ini akan sangat berpengaruh pada eksistensi negaranya. Negara dengan jiwa dan semangat kebangsaan yang berkobar maka akan bisa mempertahankan eksistensi negera tersebut dan akan diakui oleh negara lain. Sebaliknya apabila negara tersebut tidak memiliki jiwa dan semangat yang tinggi, maka pada hakikatnya eksistensi dari bangsa dan negara yang bersangkutan telah tidak ada lagi. Meskipun dalam bentuk fisik bangsa dan negara tersebut masih berdiri (Nurgiansah, 2021b).

Indonesia sebagai negara yang berdaulat dan memiliki wilayah yang sangat luas, dengan jumlah penduduk yang sangat besar dengan berbagai macam ras, suku, budaya, dan agama yang menjadikan sebuah ciri khas tersendiri dari perbedaan itu. Dengan banyaknya perbedaanperbedaan tersebut, diperlukannya nilainilai nasionalisme dalam kehidupan berbangsa di negara Indonesia. Nilai-nilai nasionalisme dalam konsep Negara Kesatuan Republik Indonesia (NKRI) salah satunya adalah Pancasila, Undang-Undang Dasar 1945, dan Semboyan Negara yaitu Bhinneka Tunggal Ika (Nurgiansah, 2021d).

Pancasila merupakan ideologi dan dasar dari Negara Kesatuan Republik Indonesia (NKRI) . Kedudukan Pancasila sebagai ideologi bangsa dan negara Indonesia, tercantum di dalam pembukaan UUD 1945 sebagai dasar Negara Kesatuan Republik Indonesia (NKRI) yang harus dilakukan secara berkesinambungan dalam kehidupan berbangsa dan bernegara. Dengan demikian, Pancasila sebagai ideologi bangsa adalah sebagai keseluruhan pandangan, cita-cita, keyakinan, dan nilai-nilai bangsa indonesia yang harus diimplementasikan di kehidupan bermasyarakat, berbangsa, dan bernegara (Asmaroini, 2017).

Penelitian ini dilakukan karena melihat keadaan generasi muda masa kini yang sudah melupakan nilai-nilai pancasila sebagai jati diri bangsanya. Padahal, generasi muda zaman sekarang sangat memiliki peluang untuk bisa mengubah kehidupan bangsanya dan generasi zaman sekarang juga akan mengalami adanya bonus demografi. Sehingga, dengan adanya keadaan ini harus bisa dijadikan sebuah peluang yang sangat berharga. Namun, pada kenyataannya masih banyak generasi muda yang melupakan jati diri bangsanya. Dengan melihat keadaan tersebut saya sebagai penulis tertarik untuk melakukan penelitian mengenai implementasi nilainilai pancasila dalam menumbuhkembangkan wawasan kebangsaan, terutama pada generasi muda (Nurgiansah, 2021c).

\section{METODE PENELITIAN}

Dalam pembuatan artikel ini penulis menggunakna metode penelitian kualitatif atau pendekatan deskriptif. Metode kualitatif ini dimana penulis mengumpulkan data-data mengenai Pancasila, Wawasan Kebangsaan, dan Implementasi Nilai-Nilai Pancasila. Penelitian ini dilakukan dengan Studi Pustaka. Sumber data yang diperoleh oleh penulis yaitu dari buku, artikel dan beberapa karya tulis ilmiah lainnya.

\section{HASIL PENELITIAN DAN PEMBAHASAN Hasil Penelitian Pancasila}

Pancasila merupakan dasar negara bangsa Indonesia yang dirumuskan pada saat diucapkannya proklamasi kemerdekaan, yaitu pada tanggal 17 Agustus 1945. Lebih tepatnya, rumusan pancasila terletak pada pembukaan UUD 45 alinea ke-4. (Hariyono, 2014) mengatakan bahwa kepentingan bangsa 
dan negara selalu menempati posisi yang dominan dalam perumusan pancasila sebagai dasar negara maupun sebagai pandangan hidup bangsa. (Aminullah, 2020) menyatakan bahwa pancasila dirumuskan oleh beberapa tokoh sejarah, diantaranya adalah pancasila menurut Mr. Moh. Yamin, pada saat sidang BPUPKI pada tanggal 29 Mei 1945, Mr. Moh. Yamin menyampaikan bahwa rumusan isi pancasila adalah sebagai berikut: 1) Prikebangsaan; 2) Prikemanusiaan; 3) Priketuhanan; 4) Prikerakyatan; 5) Kesejahteraan Rakyat.

Pancasila menurut Ir. Soekarno beliau menyampaikan isi rumusan pancasila pada saat sidang BPUPKI pada tanggal 1 Juni 1945 adalah sebagai berikut: 1) Nasionalisme / Kebangsaan Indonesia; 2) Internasionalisme / Prikemanusiaan; 3) Mufakat / Demokrasi; 4) Kesejahteraan Sosial; 5) Ketuhanan yang Berkebudayaan.

Setelah menyampaikan rumusan ke-5 sila tersebut, kemudian Ir. Soekarno meringkasnya menjadi Trisila, yaitu: 1) Sosio Nasional : Nasionalisme dan Internasionalisme; 2) Sosio Demokrasi : Demokrasi dengan Kesejahteraan Rakyat; 3) Ketuhanan yang Maha Esa. Menurut Ir. Soekarno juga, ia menyampaikan bahwa Trisula masih dapat diringkas menjadi Ekasila atau Satusila yang pada intinya merupakan Gotong Royong.

Pancasila menurut Piagam Jakarta, rumusan pancasila menurut piagam Jakarta disahkan pada tanggal 22 Juni 1945 dan memiliki isi rumusan sebagai berikut: 1) Ketuhanan dengan kewajiban menjalankan syariat islam bagi pemelukpemeluknya; 2) Kemanusiaan yang adil dan beradab; 3) Persatuan Indonesia; 4) Kerakyatan yang dipimpin oleh hikmat kebijksanaan dalam permusyawaratan perwakilan; 5) Keadilan sosial bagi seluruh rakyat Indonesia.

Dari semua rumusan di atas menghasilkan 5 sila yang sah dan benar yang tercantum dalam pembukaan UUD 1945. Hal ini diperkuat oleh adanya ketetapan MPRS NO.XXI/MPRS/1966 dan Impres No. 12 tanggal 13 April 1968, bahwa pengucapan, penulisan, dan rumusan pancasila dasar negara RI yang sah dan benar adalah sebagai mana tercantum dalam pembukaan UUD 1945.

Menurut (Sri Untari, 2012) Pancasila memiliki fungsi, diantaranya adalah sebagai berikut:

1. Pancasila sebagai Identitas dan Kepribadian Bangsa

2. Pancasila sebagai Sistem Filsafat

3. Pancasila sebagai Sumber Nilai

4. Pancasila sebagai Sistem Etika

5. Pancasila sebagai Paradigma Keilmuan Ekonomi, Politik, Hukum, dan Pendidikan

6. Pancasila sebagai Ideologi Terbuka.

Pancasila mengandung nilai-nilai sosial yang bersifat fundamental. Pancasila tumbuh dan berkembang sebagai nilai kultural nasional yang memuat unsurunsur yang dijunjung tinggi oleh semua golongan dan lapisan masyarakat Indonesia. Pancasila memberikan keyakinan bahwa suatu bangsa adalah semua orang yang berkeinginan membentuk masa depan bersama di bawah lindungan suatu negara, tanpa membedakan suku, ras, agama maupun golongan (Prayitno, 2014).

\section{Pembahasan \\ Wawasan Kebangsaan}

(Bastaman, 2008) menyampaikan bahwa wawasan kebangsaan merupakan cara pandang kita terhadap diri sendiri sebagai bangsa yang harus mencerminkan rasa dan semangat kebangsaan (karakter kebangsaan) dan mampu mempertahankan jati dirinya sebagai bangsa dari suatu negara tersebut. (Winarno, 2010) mengkategorikan perkembangan semangat kebangsaan bangsa Indonesia dalam 
beberapa kurun waktu, yaitu sebagai berikut:

1. Zaman Perintis. Semangat kebangsaan pada zaman perintis yaitu terjadi di sekitar tahun 1908, yaitu ditandai dengan kemunculan Pergerakan Nasional Budi Utomo.

2. Zaman Penegas. Semangat kebangsaan pada zaman penegas yaitu terjadi di tahun 1928 yang ditandai dengan Ikrar Sumpah Pemuda.

\section{Zaman Pendobrak. Semangat} kebangsaan pada zaman pendobrak yaitu terjadi pada tahun 1945 yang ditandai dengan Proklamasi Kemerdekaan Bangsa Indonesia.

(Bria, 2017) menyampaikan bahwa wawasan kebangsaan berkedudukan sebagai visi bangsa yang berhubungan erat dengan perjalanan bangsa menuju masa depan. Visi bangsa Indonesia yang sesuai dengan konsep wawasan kebangsaan adalah menjadi bangsa satu kesatuan dengan wilayah yang utuh.

(Winarno, 2007) menyampaikan bahwa wawasan kebangsaan memiliki tujuan yang dibedakan menjadi tujuan ke dalam dan tujuan keluar. Tujuan ke dalam yaitu memiliki tujuan untuk menjamin wujud persatuan dan kesatuan segenap aspek kehidupan nasional, diantaranya aspek politik, ekonomi, sosial budaya, dan pertahanan serta keamanan. Sedangkan tujuan keluar yaitu terjaminnya kepentingan nasional dalam dunia yang mengikuti perubahan dan perkembangan dan ikut serta melaksanakan ketertiban dunia berdasarkan kemerdekaan, perdamaian abadi dan keadilan sosial serta mengembangkan suatu kerja sama dan saling menghormati.

Menurut

menyampaikan

(Wiratmaja, bahwa

2021)

kebangsaan bagi Indonesia memiliki beberapa makna, diantaranya: Wawasan kebangsaan mengamanatkan kepeada seluruh masyarakat Indonesia untuk menempatkan persatuan, kesatuan, dan kepentingan serta keselamatan bangsa dan negara di atas kepentingan pribadi atau golongan; Wawasan kebangsaan tidak memberikan tempat kepada patriotisme yang licik; Wawasan kebangsaan mengembangkan persatuan bangsa Indonesia sedemikian rupa sehingga asas semboyan Bhinneka Tunggal Ika dapat diperthankan; Dengan wawasan kebangsaan yang berlandas pada pandangan pancasila, bangsa Indonesia telah berhasil merintis jalan untuk menjalani misinya di tengah-tengah tata kehidupan di dunia; Negara Kesatuan Republik Indonesia (NKRI) yang telah merdeka, bersatu, berdaulat, adil, dan makmur bertekad untuk mewujudkan bangsa Indonesia yang maju dan mandiri serta sejahtera maupun lahir batin, dan akan sejajar dengan bangsa lain yang sudah maju (Nurgiansah, 2020).

Nilai wawasan kebangsaan yang terwujud di dalam persatuan dan kesatuan bangsa, memiliki 6 dimensi yang bersifat mendasar dan fundamental, diantaranya sebagai berikut:

1. Penghargaan terhadap harkat dan martabat manusia sebagai makhluk ciptaan Tuhan Yang Maha Esa.

2. Bertekad bersama untuk kehidupan berbangsa yang merdeka, bebas, dan bersatu.

3. Cinta akan bangsa dan tanah air.

4. Berdemokrasi dan berkedaulatan rakyat.

5. Kesetiakawanan sosial.

6. Masyarakat yang adil dan makmur.

Wawasan kebangsaan sangat berkaitan erat dengan pengetahuan akan jati diri bangsa Indonesia. Namun, sekarang dengan maraknya globalisasi dan semakin mudahnya budaya asing masuk ke Indonesia, wawasan kebangsaan harus tetap bisa dipertahankan dan 
ditumbuhkembangkan, agar eksistensi persatuan dan kesatuan bangsa Indonesia tetap bisa dipertahankan dan bisa bersaing dengan negara-negara maju di dunia. Oleh karena itu, upaya yang dilakukan bisa dengan cara mengimplementasikan nilainilai pancasila di kehidupan masyarakat bangsa Indonesia agar dapat menumbuhkembangkan kembali wawasan kebangsaan yang kini semakin terkikis oleh perkembangan zaman.

\section{Implementasi Nilai Pancasila dalam Menumbuhkembangan Wawasan Kebangsaan di Kehidupan Bangsa Indonesia}

Globalisasi sangat berdampak bagi seluruh dunia, tidak terkecuali tanah air kita ini yaitu negara Indonesia. Salah satu dampak dari globalisasi adalah perkembangan teknologi informasi yang semakin cepat. Perkembangan teknologi informasi menimbulkan dampak yang besar bagi kehidupan berbangsa dan bernegara di Indonesia. Hal ini menyebabkan timbulnya kekhawatiran akan hilangnya nilai-nilai kebudayaan Indonesia, yang tidak bisa dihindari bahwa kebudayaan Indonesia akan tergantikan oleh budaya global. Terlebih pemahaman dan kesadaran akan wawasan kebangsaan di masyarakat Indonesia semakin menurun (Nurgiansah et al., 2020).

(Irhandayaningsih,

mengatakan bahwa permasalahan yang dihadapi bangsa indonesia dewasa ini adalah memudarnya semangat nasionalisme dan patriotisme di kalangan generasi muda. Hal ini disebabkan banyaknya pengaruh budaya asing yang banyak masuk di negara kita, akibatnya banyak generasi muda yang melupakan budaya sendiri karena menganggap bahwa budaya asing merupakan budaya yang lebih modern daripada budaya bangsa sendiri.
(Danniarti, 2017) menyampaikan bahwa melihat perkembangan wawasan kebangsaan yang dimiliki komponen bangsa Indonesia saat ini, apabila dibiarkan maka Negara Kesatuan Republik Indonesia yang sangat kita cintai akan berimplikasi pada hal-hal berikut ini:

1. Tidak terlaksananya pemahaman nilainilai pancasila terutama pada paham kebangsaan.

2. Tidak terlaksananya pemahaman terhadap nilai-nilai pancasila terutama pada rasa kebangsaan.

3. Tidak terlaksananya pemahaman terhadap nilai-nilai pancasila terutama pada semangat kebangsaan.

Untuk menumbuhkembangkan kembali wawasan kebangsaan di Indonesia, upaya yang bisa dilakukan adalah dengan cara mengamalkan dan menyadari kembali nilai-nilai yang terkandung dalam pancasila. Sebab nilainilai yang terkandung dalam pancasila merupakan nilai-nilai yang diambil dari kebudayaan bangsa Indonesia, yang bertujuan untuk menjaga kesatuan dan persatuan bangsa Indonesia. nilai-nilai pancasila yang bisa dilakukan di kehidupan berbangsa, diantaranya adalah:

1. Pada sila pertama, yaitu "Ketuhanan Yang Maha Esa". Nilai-nilai pancasila yang bisa kita lakukan dalam kehidupan sehari-hari, yaitu: Mengimani adanya Tuhan yang Maha Esa serta mematuhi perintah dan menjauhi larangan-Nya; Saling bertoleransi antar umat beragama; Saling menghormati dan tidak merendahkan agama dan pemeluk agama lainnya (Dewantara, Nurgiansah, et al., 2021).

2. Pasa sila kedua, yaitu "Kemanusiaan yang Adil dan Beradab". Nilai-nilai pancasila yang bisa kita lakukan dalam kehidupan sehari-hari, yaitu: Mengakui persamaa hak, kewajiban dan kedudukan semua orang sama di mata 
hukum, sosial, agama dan lainnya; Mengedepankan sikap toleransi atau tenggang rasa antar masyarakat; Berteman dengan siapa saja tanpa membeda-bedakan ras, suku, agama dan lainnya (Dewantara \& Nurgiansah, 2021).

3. Pada sila ketiga, yaitu "Persatuan Indonesia". Nilai-nilai pancasila uang bisa kita lakukan dalam kehidupan sehari-hari, yaitu: Bangga menggunakan bahasa Indonesia sebagai bahasa dalam pergaulan sehari-hari; Melestarikan kebudayaan Indonesia seperti baju adat, tarian daerah, alat musik daerah dan lain sebagainya dalam kehidupan sehari-hari; Saling bekerja sama dalam menjaga keutuhan NKRI dengan berpegang teuh kepada nilai-nilai pancasila.

4. Pada sila keempat, yaitu "Kerakyatan yang Dipimpin oleh Hikmat Kebijaksanaan dalam Permusyawaratan dan Perwakilan". Nilai-nilai pancasila yang bisa kita lakukan dalam kehidupan sehari-hari, yaitu: Bermusyawarah dalam setiap pengambilan keputusan; Mengedepankan toleransi dan keadilan dalam mengemukakan dan mendengarkan pendapat dalam musyawarah; Keputusan akhir musyawarah harus disetujui oleh semua pihak karena musyawarah dilakukan untuk menghasilkan keputusan bersama.

5. Pada sila kelima, yaitu "Keadilan Sosial Bagi Seluruh Rakyat Indonesia". Nilainilai pancasila yang bisa kita lakukan dalam kehidupan sehari-hari, yaitu: Mengedepankan sikap adil kepada sesama manusia; Melaksanakan kewajiban dan menghormati hak orang lain; Mengedepankan kesejahteraan seluruh rakyat Indonesia dibandingkan dengan kepentingan pribadi ataupun golongan (Dewantara, Hermawan, et al., 2021).
Dengan mengimplementasikan nilainilai pancasila dalam menumbuhkembangkan wawasan kebangsaan diatas, maka kehidupan berkebangsaan akan berlangsung dengan efektif, sejalan dengan gerak perubahan kehidupan berbangsa dan bernegara seluruh warga negara Indonesia.

Menurut (Janah, 2019) Pancasila yang sudah sejak dahulu diciptakan sebagai dasar negara dan sudah sejak nenek moyang kita gunakan sebagai pandangan hidup bangsa, maka sudah seharusnya dijadikan pedoman bagi bangsa Indonesia dalam kehidupan berbangsa dan bernegara. Demikian juga bagi generasi muda, Pancasila yang mulai kehilangan pamornya di kalangan generasi muda diharapkan akan muncul kembali kejayaannya apabila generasi muda mulai sadar dan memahami fungsi dan nilai Pancasila serta menerapkannya dalam kehidupan sehari-hari.

Seperti yang bisa kita rasakan saat ini bahwa kemajuan globalisasi menyebabkan banyaknya budaya asing yang masuk ke Indonesia. Salah satunya adalah saat ini para generasi muda yang sangat menyukai budaya korea selatan dari pada budaya bangsanya sendiri. Banyak dari mereka yang lebih tahu budaya asing dari pada budaya lokal. Oleh karena itu, diperlukan adanya penguatan wawasan kebangsaan melalui implementasi nilai-nilai pancasila. Karena apabila negara kita sudah kuat wawasan kebangsaannya, maka perkembangan informasi yang disebabkan oleh globalisasi akan bisa dilalui dengan mudahnya dan eksistensi negara Indonesia akan diakui oleh bangsa lainnya dan tidak akan hilang walaupun negara tersebut masih berdiri.

\section{KESIMPULAN}

Globalisasi menyebabkan banyaknya budaya asing yang masuk ke Indonesia. 
Terlebih pada masa kini budaya korea selatan yang menjadi salah satu tantangan bagi bangsa Indonesia, karena sebagian besar generasi muda masa kini sangat tertarik dengan budaya korea selatan bahkan bisa sampai melupakan budayanya sendiri. Supaya tidak melemahnya wawasan kebangsaan, maka kita memerlukan penguatan wawasan kebangsaan dengan mengimplementasikan nilai pancasila di kehidupan bangsa Indonesia. Nilai-nilai yang terkandung di dalam pancasila dapat membantu kita untuk menumbuhkembangkan wawasan kebangsaan di kehidupan bangsa Indonesia. Salah satu implementasi nilai pancasila dalam menumbuhkembangkan wawasan kebangsaan adalah dengan menghargai, menghormati dan saling menjaga satu kesatuan bangsa tanpa membeda-bedakan suku, ras, agama, dan lain sebagainya. Karena apabila wawasan kebangsaan kita sudah kuat maka kita akan dengan mudahnya melalui tantangan globalisasi tersebut.

\section{DAFTAR PUSTAKA}

Aminullah, R. dan Umam, M. (2020). Pancasila sebagai Wawasan Nusantara. Al-Allam, 1(1).

Asmaroini, A.P. (2017). Menjaga Eksistensi Pancasila dan Penerapannya Bagi Masyarakat Di Era Globalisasi. JPK: Jurnal Pancasila dan Kewarganegaraan, 1(2).

Bastaman, H.D. (2008). Membangun Kembali Jati Diri Bangsa. Jakarta: PT Elex Media Komputindo.

Bria, M.E. (2017). Penguatan Wawasan Kebangsaan Peserta Didik di Daerah Perbatasan Indonesia-Timor Leste Melalui Pembelajaran Pendidikan Kewarganegaraan. Prosiding Konferensi Nasional Kewarganegaraan III.

Danniarti, R. (2017). Implementasi Nilai-Nilai Pancasila sebagai Pendukung Tumbuh Kembang Wawasan Kebangsaan pada Mata Pelajaran PPKn di SMPN 7 Palembang. JMKSP: Jurnal Managemen, Kepemimpinan, dan Supervisi Pendidikan, 2(2).

Dewantara, J. A., Hermawan, Y., Yunus, D., Prasetiyo, W. H., Efriani, Arifiyanti, F., \& Nurgiansah, T. H. (2021). Anti-Corruption Education as an Effort to Form Students With Character Humanist and Law-Compliant. Jurnal Civics: Media Kajian Kewarganegaraan, 18(1), 7081.

Dewantara, J. A., \& Nurgiansah, T. H. (2021). Building Tolerance Attitudes Of PPKN Students Through Multicultural Education Courses. Jurnal Etika Demokrasi, 6(1), 103-115.

Dewantara, J. A., Nurgiansah, T. H., \& Rachman, F. (2021). Mengatasi Pelanggaran Hak Asasi Manusia dengan Model Sekolah Ramah HAM (SR-HAM). Edukatif: Jurnal Ilmu Pendidikan, $3(2), 261-269$.

Hariyono. (2014). Ideologi Pancasila Roh Progresif Nasionalisme Indonesia. Malang: Instans Publishing.

Irhandayaningsih, A. (2012). Peranan Pancasila Dalam Menumbuhkan Kesadaran Nasionalisme Generasi Muda di Era Global. Humanika.

Lestari, E.Y. Janah, M. \& Wardanai, P.K. (2019). Menumbuhkan Kesadaran Nasionalisme Generasi Muda di Era Globalisasi Melalui Penerapan Nilai-Nilai Pancasila. Adil Indonesia Jurnal, 1(1).

Muslimin, H. (2016). Tantangan Terhadap Pancasila sebagai Ideologi dan Dasar Negara Pasca Reformasi. Jurnal Cakrawala Hukum, 7(1).

Nurgiansah, T. H. (2020). Fenomena Prostitusi Online Di Kota Yogyakarta Dalam Persfektif Nilai Kemanusiaan Yang Adil Dan Beradab. Jurnal Kewarganegaraan, 17(1), 27-34. https://doi.org/10.24114/jk.v17i1.14208 
Nurgiansah, T. H. (2021a). Pendidikan Pancasila. In Solok: CV Mitra Cendekia Media.

Nurgiansah, T. H. (2021b). Pendidikan Pancasila Sebagai Upaya Membentuk Karakter Jujur. Jurnal Pendidikan Kewarganegaraan Undiksha, 9(1), 33-41.

Nurgiansah, T. H. (2021c). Petuah Pendidikan Kewarganegaraan Dalam Kontestasi Politik. AoEJ: Academy of Education Journal, 12(1), 39-47.

Nurgiansah, T. H. (2021d). The Role of Citizenship Education in Building Bantul Community Political Participation in The Pandemic Covid 19. Prosiding Seminar Nasional Pendidikan Dan Kewirausahaan, 4(1), 1-4.

Nurgiansah, T. H., Dewantara, J. A., \& Rachman, F. (2020). The Implementation of Character Education in the Civics Education Syllabus at SMA Negeri 1 Sleman. Jurnal Etika Demokrasi, 5(2), 110-121.

Prayitno, \& Belferik. (2014). Pendidikan Karakter dalam Pembangunan Bangsa. Medan. Universitas Negeri Medan.

Sri Untari. (2012). Pancasila Dalam Kehidupan Bermasyarakat, Berbangsa dan Bernegara. Pendidikan Pancasila Topik Aktual Kenegaraan dan Kebangsaan. Malang: Universitas Negeri Malang.

Suhady, Idup dan A.M. Sinaga. (2006). Wawasan Kebangsaan Dalam Kerangka NKRI. Jakarta: Lembaga Administrasi Negara-Republik Indonesia.

Winarno. (2007). Paradigma Baru: Pendidikan Kewarganegaraan. Bandung: PT Bumi Aksara.

Wiratmaja, I.N. Suacana, I.W.G. Sudana, I.W. (2021). Penggalian Nilai-Nilai Pancasila Berbasis Kearifan Lokal Bali Dalam Rangka Penguatan Wawasan Kebangsaan. POLITICOS: Jurnal Politik dan Pemerintahan, 1(1). 43-52.

Winarno. (2010). Paradigma Baru Pendidikan Kewarganegaraan. Jakarta: PT Bumi Aksara. 